\title{
Re: Screening for retinopathy of prematurity and treatment outcome in a tertiary hospital in Hong Kong \\ Hong Kong Med J 2017;23:316
}

DOI: 10.12809/hkmj176306

To the Editor-We read with interest the elegant study by Iu et $\mathrm{al}^{1}$ on the prevalence and severity of retinopathy of prematurity (ROP) in a tertiary hospital in Hong Kong. Compared with their data in which the incidence of ROP was $16.9 \%$ in 89 premature infants screened over 1 year, ${ }^{1}$ our analysis of 602 infants screened over 7 years $^{2}$ and another local study of 513 infants over 5 years $^{3}$ revealed a ROP prevalence of 28.2 and $18.5 \%$, respectively. We would like to highlight the point that the prevalence rates could be related to the case-mix. We had a larger proportion of high-risk infants. Our youngest mean gestational age was $29^{+3}$ weeks compared with $30^{+2}$ weeks in Iu et al's study ${ }^{1}$ and 30 weeks in Yau et al's study. ${ }^{3}$ We also had a higher proportion of extremely low birth weight (ELBW) infants $\left(<1000 \mathrm{~g} ; 24.1 \%^{2}\right.$ vs $\left.19.1 \%^{1}\right)$. This may reflect socio-economic differences and the complexity of cases. Among ELBW infants, however, a comparable percentage $\left(70.6 \%^{1}\right.$ vs $\left.71.7 \%^{2}\right)$ developed ROP and treatment rates among the studies were also very similar $\left(3.4 \%^{1}, 3.8 \%^{2}\right.$, and $\left.3.7 \%^{3}\right)$.

While all three studies adopted the Royal College of Ophthalmologists ROP guidelines, ${ }^{1-3} \mathrm{Iu}$ et $\mathrm{al}^{1}$ identified 11 infants who would not have been screened had the American Academy of Pediatrics' criteria been applied, and none of whom developed

ROP. Within our cohort, three of 93 infants who exceeded the American screening guidelines developed ROP with subsequent spontaneous resolution. This highlights the need for future reevaluation of guideline selection.

Karen KW Chan, MB, BS

Julie YC Lok, MB, BS, MRCSEd

Wilson WK Yip *, FHKAM (Ophthalmology)

Alvin L Young, FHKAM (Ophthalmology)

Department of Ophthalmology and Visual Sciences, The Chinese University of Hong Kong, Prince of Wales Hospital, Shatin, Hong Kong

*Corresponding author: ywk806@ha.org.hk

\section{References}

1. Iu LP, Lai CH, Fan MC, Wong IY, Lai JS. Screening for retinopathy of prematurity and treatment outcome in a tertiary hospital in Hong Kong. Hong Kong Med J 2017;23:41-7.

2. Luk AS, Yip WW, Lok JY, Lau HH, Young AL. Retinopathy of prematurity: applicability and compliance of guidelines in Hong Kong. Br J Ophthalmol 2017;101:453-6.

3. Yau GS, Lee JW, Tam VT, et al. Incidence and risk factors of retinopathy of prematurity from 2 neonatal intensive care units in a Hong Kong Chinese population. Asia Pac J Ophthalmology (Phila) 2016;5:185-91. 